\title{
Oral rehabilitation noninvasive in a patient with junctional epidermolysis bullosa: Case report
}

\author{
Eliane Okayama ${ }^{1}$, Vanda Rieko Fujita Miyazaki ${ }^{1}$, Idiberto Jose Zotarelli Filho ${ }^{2 *}$, Reinaldo Missaka ${ }^{2}$, Elias Naim Kassis ${ }^{1,2}$ and Ricardo Jun \\ Furuyama ${ }^{1,2}$ \\ ${ }^{1}$ University Center North Paulista (Unorp) - São José do Rio Preto SP, Brazil \\ ${ }^{2}$ Post Graduate and Continuing Education (Unipos), São José do Rio Preto SP, Brazil
}

\begin{abstract}
Epidermolysis bullosa occurs in all races worldwide and not differ on incidence between the genders. It is a very rare disease and its occurrence in the population is not known precisely, but it is estimated that the prevalence of dystrophic form is between one case in every 20,000 to 130,000 people and the way acquired a case for 1.3 million people. According to epidemiological data from the United States, there are 50 cases of epidermolysis bullosa $1,000,000$ live births. The present study is an attempt to rehabilitate the patient's dentition in question through two hybrid dentures supported on the teeth using a non-invasive treatment and in an efficient manner. Case Report, CF patient, 42 years old, male, white, attended the clinic specialized in prosthodontics University Center North Paulista (UNORP) due to their need for oral rehabilitation. In discussion, by treating able to improve masticatory function, besides the same show already be accustomed to the use of hearing aids without appearance of lesions or blisters and very satisfied with the aesthetic result, increasing their self-esteem. In conclusion, the rehabilitation by means of two hybrid supported denture on teeth has been successfully performed via a non-invasive and efficient treatment.
\end{abstract}

\section{Introduction}

Epidermolysis bullosa (EB) occurs in all races worldwide and no difference in incidence between the sexes has been observed. It is a very rare disease and its occurrence in the population is not known precisely, but it is estimated that the prevalence of dystrophic form is about one case in every 20,000 to 130,000 people and the occurrence of a case in 1.3 million people [1]. EB can affect individuals of different age groups, but most cases have been diagnosed during childhood [2].

EB does not present accurate data on the prevalence and incidence, despite its occurrence in Europe (all types of EB) is estimated to be in about 60 million people [3]. The effect is believed to be about 19 per million births. The incidence is not affected by race or the ethnic group, and the disease also affects both sexes. EB simplex is the most common form (92\%), followed by dystrophic EB (5\%) and finally the junctional EB (1\%). An American study suggested that for every 350 people, one carries a recessive gene for EB congenital [4].

According to epidemiological data from the United States, there are 50 cases of epidermolysis bullosa 1,000,000 live births [5]. Northern Ireland data showed that, for 23 years (1962-1984), 48 cases of EB were identified which were distributed as follows: 31 cases of simple EB (65\%), one case of junctional EB (2\%), 12 cases dystrophic EB (25\%) and four cases of acquired form (8\%). In Brazil, there was no epidemiological data recorded [6].

The demand for dental treatment is often delayed, requiring surgery/ restorer, where some specific care should be taken, such as avoiding unnecessary trauma to the oral mucosa, prosthesis and restorations should be carefully tailored and polished, secondary infections must be prevented. The use of antiseptics, local anesthetics should be avoided whenever possible to reduce bubble formation [7]. If needed, it must be injected deep into the tissues very slowly to prevent tissue distortion. Placing removable partial dentures and denture should be studied, since the lesions can appear by friction thereof with the mucosa [8].

These are well planned and executed, it is an interesting alternative to oral rehabilitation of these patients, since the placement of implants can become very aggressive treatment in such cases. Unfortunately, as mentioned earlier, to date there is no curative treatment for this disease, so the best thing to do for these patients is to improve their quality of life through a supportive family and a multidisciplinary team [9].

The importance of this disease for dentistry is the fact that some forms of epidermolysis bullosa have oral manifestations, like bubbles on the palate, tongue, floor of the mouth, lips [1], as well as dental and microstomia dysplasias, which hinders the realization of conventional dental treatment. It is observed that in epidermolysis bullosa simplex, the dominant dystrophic and acquired dental changes do not occur [10].

In recessive dystrophic epidermolysis bullosa, intra-oral manifestations are severe and debilitating. Buccal sulci are obliterated by scarring, ankyloglossia is common and the language becomes smooth and atrophic $[1,11]$. Teeth are often surrounded by decay to the point of being destroyed by the gum. They can also be hypoplastic, with enamel failures and present supernumerary or impacted $[3,12]$.

Correspondence to: Idiberto José Zotarelli Filho, Unipos - Post Graduate and Continuing Education, Street Ipiranga, 3460, São José do Rio Preto SP Brazil 15020-040, Tel: +55(17) 98166-6537/ +55(17) 98803-7459; E-mail: m.zotarelli@gmail.com

Key words: epidermolysis bullosa, oral manifestations, oral rehabilitation

Received: May 07, 2015; Accepted: June 18, 2015; Published: June 22, 2015 
The emergence of bubbles in mouth may be caused due to nursing or dental treatment being very painful [3]. In the junctional EB, the intraoral bubbles are very extensive, causing serious problems in food and can also occur marked changes in the formation of enamel and dentin of deciduous teeth [14].

In general, oral involvement epidermolysis bullosa affects all oral surfaces and disease progression some complications can arise as a result of increasing severity and bubbles [15]. Mucous can become adhered to the gingival edentulous areas in or on the tooth neck as a result of contractions of scars or blistering in the region [1]. The teeth, the changes have been described as deformities, birth defects and abnormal formation of enamel. Supernumerary and impacted teeth are commonly found as well as extensive tooth decay, abscesses and scarification of periodontal tissues [3].

There are several limitations that the dentist has to deal with patients suffering from this disease. The very fact that there is no specific treatment for the disease is quite disturbing, and which may exist are palliative therapies that can come to promote a temporary improvement, as the use of vitamin $\mathrm{A}$ and $\mathrm{E}$, in order to reduce the severity and rate of occurrence of bubbles, but the manner in which such agents work is still unknown [3].

Thus, the aim of the present study is the attempt to rehabilitate the patient's dentition in question through two hybrid dentures supported on the teeth using a non-invasive treatment and in an efficient manner.

\section{Case report}

FC patient, 42 years old, male, white, attended the clinic specialized in prosthodontics University Center North Paulista (UNORP) due to their need for oral rehabilitation. The patient was a carrier of junctional epidermolysis bullosa which was confirmed by histopathology. The clinical follow-up and treatment was done at St. Joseph's Hospital de Base do Rio Preto. Treatment began 12 years ago, with daily use of $60 \mathrm{mg}$ of corticosteroids, which resulted in the emergence of other problems such as cataracts, osteoporosis and tachycardia. To work around this, the dose of this medication was reduced and associated with the use of dapsone $100 \mathrm{mg}$. The use of steroids can never be suspended. However, the patient dose has already been reduced to 15 $\mathrm{mg}$ daily and the purpose is to stabilize this dose at 5 to $10 \mathrm{mg}$ daily (Figure 1).
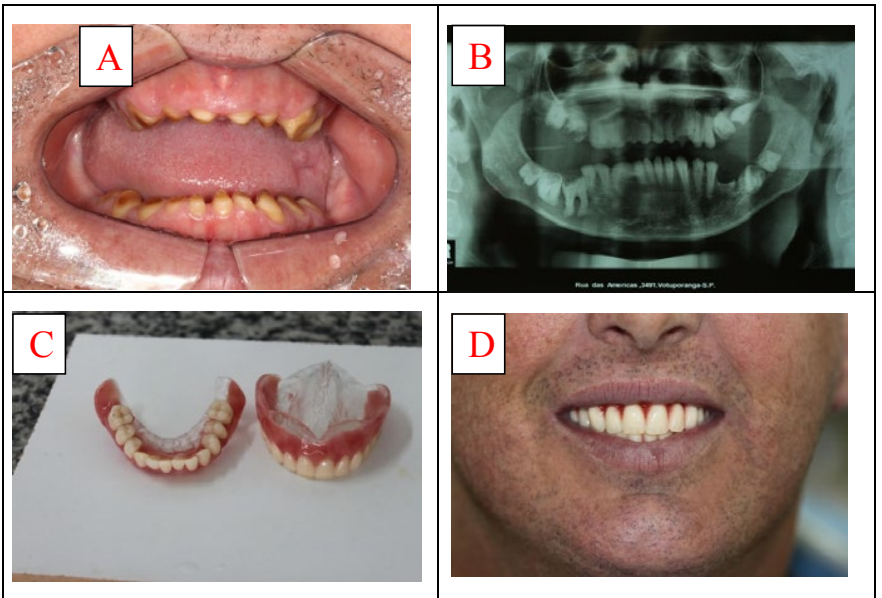

Figure 1. (A) Real view (B) Panoramic view (C and D) Images of the case of epidermolysis bullosa and two hybrid dentures which was supported on teeth.
The patient did not report any family history of the disease. During the clinical examination no blister or skin lesions were reported as the disease was kept under control through the treatment performed. His oral examination, they observed that all the teeth were with poor training, as well as impacted and ankylosed teeth. Patient did not report any pain or sensitivity in teeth as well as the absence of periodontal disease. It was observed the presence in the panoramic radiograph of teeth affected and possibly several ankylosed as well as being reported by the patient's own failure in extraction of the tooth.

The recommended treatment in this case was the production of hybrid dentures, precisely because of the impossibility of extraction of ankylosed and impacted teeth. Moreover, since the teeth that serve to support the total hybridizes prosthesis, although very few poorly formed and having enamel and dentin structures, had no pain or sensitivity, thus discarded the need for endodontic treatment.

The first step was to hold impressions of the maxillary and mandibular arches with an elastic material in a single impression that in the case was the condensation silicone, thus allowing the removal of free mucosa and the right impression of anatomical structures. From this, we obtained the models which were manufactured the evidence bases, which allowed the records of maxillo-mandibular relations of the patient.

The evidence bases were made bypassing the regions of checks and bridles and respecting boundaries in models where the upper arch covers up $3.4 \mathrm{~mm}$ of mobile mucosa, skirts to the pterygoid angle (more descending part of the tuber) and the posterior boundary coincides with the vibrating line (soft palate/hard palate). In the lower jaw, it should cover $2 / 3$ of the retromolar papilla from 2.0 to $3.0 \mathrm{~mm}$ to milioidea line passing exactly the oblique line and around the apophysis genesis, according to a procedure by Tadachi Tamaki.

Upper wax plan observing the lip support, the visible portion of wax with the lip at rest which normally is $2.0 \mathrm{~mm}$ below the lip tubercle and lateral at the time of labial. In this case, we chose to leave visible portion of the wax with a measure greater than $2.0 \mathrm{~mm}$ because the patient is young and has an arched lip. Then he went to the conformation of the posterior occlusal plan, verified by Fox strip where there was his parallelism with the line from the tragus to the nose wing and also its parallelism with bipupilar plan.

After the making of the wax top plan determined the occlusal vertical dimension (OVD). With the patient in perfect balance position, at rest, with the tongue on the palate, tight lips and nasal respiration, and the measure aid of Willis, measured the distance from the base of the nose to the development, where the size was obtained vertical rest (DVR). Thus, $3.0 \mathrm{~mm}$ is subtracted from this measure, which corresponds to the freeway space (EFL), thereby determining a vertical dimension of occlusion of the patient. Equation 1: DVO=DVR-EFL. Set the compass that extent.

Fashioned is now the lower wax plan, where this still in plastic state, was taken to the patient's mouth, it was yielding to higher wax plan compression, until the extent of the vertical dimension of occlusion obtained by compass. With the two planes wax in place, it is the correctness of the mouthpiece is fashioned corridor and the smile line markings, the average line and the line to canines.

The facial bow was mounted in the Frankfurt plane, moved higher wax plan for the semi-adjustable articulator, recording the intercondylar distance from the patient, and then the top model was secured. After that, central relationship took place where the correct 
horizontal positioning of the jaw relative to the jaw was determined. It was done through direct method of registration or bite which consists of making the patient perform repetitive bites on the wax plans with a small degree of mouth opening. It was done until the most frequent occlusion position was observed, where they were fixed in the observed position. Now, the lower model was set up in semi-adjustable articulator, enabling the realization of the teeth assembly.

Then the selection of the teeth was made, observing the patient characteristics such as face shape, skin color and age. As the patient was young, the teeth chosen were lighter in color (A2-Vitta Scale) and more than $2.0 \mathrm{~mm}$ of the teeth was left while in rest position, due to the curved shape of your lips.

Then, the test of the teeth was carried out, checking both the aesthetics and phonetics and closure. Finally with dentures acrylicize and position, the perfect adaptation on the teeth was attained. The gingival characterization was made by Thomas Gomes system, thus ensuring ease the prosthesis. After installation of the prosthesis, the periodic control was done for the patient to adjust, and it was found to be free of lesions or blisters on the mucosa.

\section{Discussion}

The oral rehabilitation of these patients should be planned individually, as per the specific need and limitation. According to the clinical findings of this report, namely the large presence of impacted and ankylosed teeth, tooth extraction was contraindicated because it would have been a very invasive and aggressive procedure. The presence of sound teeth with a typical size and anatomy, made us to choose the preparation of hybrid dentures, once these have been fitted on the teeth, giving increased stability and reducing its friction with the mucosa of the patient.

With this treatment we can improve the chewing function. Besides, we are already accustomed to the use of hearing aids without appearance of lesions or blisters and very satisfied with the aesthetic result, increasing self-esteem, as reported in the article Brooks et al., 2008 [11].

Extending the argument, epidermolysis bullosa (EB) is a hereditary dermatosis, relatively rare, characterized by the development of blisters on the skin-mucous region of the whole body in response to a minimum trauma to heat or with no apparent cause [1]. It is a disease that can affect the entire population, any racial group and also men and women [2].

Physiopathologically, EB is caused by the weakness of epidermal basal cells, which when ruptured allows the space produced in the epidermis is filled with extracellular fluid and consequently the formation of bubbles [1]. The epidermolysis bullosa classification is made according to its mode of inheritance. The distribution of lesions and morbidity associated with the disease can be distinguished in three major groups: simplex, junctional and dystrophic, with more than 20 subtypes [2].

Further, in EB simplex, cleavage occurs within the [2] epidermises, i.e., the lesions are formed as a result of severe degeneration of basal cells of the epidermis by altering the keratin. This type of epidermolysis leaves no scars or causes dental changes [1]. Already in junctional $\mathrm{EB}$, cleavage is located in subepidermal Junction, in the lamina lucida [4], producing severe events occurring anemia, growth retardation, hyperkeratosis foot plant, which can be fatal [1].

In dystrophic epidermolysis bullosa, cleavage also occurs in subepidermal joint, but below the lamina densa. This can be recessive or dominant, recessive type being the most severe form of the disease and the patient does not reach adulthood [1]. Importantly, one of the mildest case of existence with acquired epidermolysis bullosa has been described above. Moreover, EB is a disease that can seriously affect the quality of life of patients [6].

Some difficulties complicate the rehabilitation treatment of these patients, as the fragility of the mucosa and the microstomia [6]. The lesions in the oral mucous membrane can be so severe that they interfere with nutrition as a result of the difficulty of food due to pain [7].

The administration of local anesthetic can induce the formation of bubbles intraoral, but this can be avoided with a slow injection of the solution. General anesthesia may be indicated in some cases, depending upon the patient's cooperation and also the extent of the dental treatment plan [6], but this maneuver becomes complicated because the intubation may predispose the patient to a high risk of pharyngeal and tracheal lesions [8].

Furthermore, EB is a disease that does not affect the osseointegration, so treatment with bone grafts and implants can be chosen [9], if well indicated. Multiple extractions should not be the treatment of choice and the installation of dentures is still a controversial issue because of the risk of blistering and erosive lesions [8], but studies have shown that when these installed, the lesions formed quickly healed after these be adjusted [7].

\section{Conclusion}

The rehabilitation by means of two hybrid dentures supported on teeth was carried out successfully by means of a non-invasive and efficient treatment.

\section{Competing interests}

The authors declare that they have no competing interests.

\section{Acknowledgement}

The work was financially supported by the Unipos of Sao Jose do Rio Preto - Brazil. We appreciate the support of Famerp and Base Hospital of Sao Jose do Rio Preto - Brazil, also Duke University (Durham, NC, USA) in the field of research and statistical studies.

\section{References}

1. Angelo MMFC, França DC, Lago DBR, Volpato LER (2012) Manifestações Clínicas da Epidermólise Bolhosa: Revisão de Literatura. Pesquisa Brasileira de odontopediatria e Clinica Integrada, João Pessoa, 12: 135-141.

2. Almeida, HLJ (2012) Genética Molecular das Epidermólises Bolhosas. Anais brasileiros de dermatologia, Rio de Janeiro 77: 519-532.

3. Santos KK, Difabio LFG, Santos MTBR, Soares Júnior LAV (2011). Efetividade do uso de substâncias lubrificantes orais em pacientes com epidermólise bolhosa. $R G O$ Rev Gaúcha Odontol 59: 209-213.

4. Dures E, Morris M, Gleeson K, Rumsey N (2011) The psychosocial impact of epidermolysis bullosa. Qual Health Res 21: 771-782. [Crossref]

5. Candel-Marti ME, Ata-Ali J, Peñarrocha-Oltra D, Peñarrocha-Diago M, Bagán JV (2011) Dental implants in patients with oral mucosal alterations: An update. Med Oral Patol Oral Cir Bucal 16: e787-793. [Crossref]

6. Silva LCF, Bastos AS, Araújo MS, Viana VS, Piva MR (2011) Manifestações Estomatológicas da Epidermólise Bolhosa. Revista de Cirurgia e Traumatologia BuçoMaxilo-Facial, Aracajú, 3: 19-23.

7. Levy BP, Reeve CM, Kierland RR (2010) The oral aspects of epidermolysis bullosa dystrophica: a case report. 55-58. 
8. Brandling-Bennett HA, Morel KD (2010) Common wound colonizers in patients with epidermolysis bullosa. Pediatr Dermatol 27: 25-28. [Crossref]

9. Larrazabal-Morón C, Boronat-López A, Peñarrocha-Diago M, Peñarrocha-Diago M (2009) Oral rehabilitation with bone graft and simultaneous dental implants in a patien with epidermolysis bullosa: a clinical case report. J Oral Maxillofac Surg 67: 14991502. [Crossref]

10. Siqueira MA, de Souza Silva J, Silva FW, Díaz-Serrano KV, Freitas AC, et al. (2008) Dental treatment in a patient with epidermolysis bullosa. Spec Care Dentist 28: 92-95. [Crossref]

11. Brooks JK, Bare LC, Davidson J, Taylor LS, Wright JT (2008) Junctional epidermolysis bullosa associated with hypoplastic enamel and pervasive failure of tooth eruption:
Oral rehabilitation with use of an overdenture. Oral Surg Oral Med Oral Pathol Oral Radiol Endod 105: e24-28. [Crossref]

12. Alves PVM, Alves DKM, Maciel JVB, Bolognese AM (2007) Atendimento multidisciplinar do paciente ortodôntico com epidermólise bolhosa. Revista Dental Press de Ortodontia e Ortopedia Facial, Maringá, 12: 30-37.

13. Azrak B, Kaevel K, Hofmann L, Gleissner C, Willershausen B (2006) Dystrophic epidermolysis bullosa: oral findings and problems. Spec Care Dentist 26: 111-115. [Crossref]

14. Neville BW, Damm DD, Allen CM, Bouquot JE (1995) Patologia Oral and Maxilofacial Rio de Janeiro: Guanabara koogan.

15. Tamaki T (1983). Dentaduras Completas. (4th edn). São Paulo: Sarvier.

Copyright: $@ 2015$ Okayama E. This is an open-access article distributed under the terms of the Creative Commons Attribution License, which permits unrestricted use, distribution, and reproduction in any medium, provided the original author and source are credited. 